\title{
Mental Health Status and Influencing Factors Among Family Caregivers of Hearing-impaired Children
}

\author{
Siqi Ma \\ The Second High School Attached to Beijing Normal University International Department, Beijing. \\ *Corresponding author. Email: masiqi050517@163.com
}

\begin{abstract}
Objective To investigate the mental health status and influencing factors among family caregivers of hearing-impaired children.

Methods: This survey adopts the questionnaire survey method. Questionnaires were distributed to a total of 200 family caregivers of hearing-impaired children from the Kindergarten and the Care Centre, giving an overall response rate of 56.5\% (113 respondents). Meanwhile, factor analysis revealed that GHQ-12[3] was a measure of psychological distress, with a three-factor structure (Psychological Distress, Social and Emotional Dysfunction and Cognitive Disorder)[4].

Results : There are 3 results in the following essay. Some of the result 2 are universal, the other's are not significant. The tendency of influence is that each increase in the monthly household income of the family caregiver was associated with better mental health; and the older the first child is, the better the mental health status of his family caregivers. As for the result 3, the higher the mean score, the worse the mental health of the family caregiver. The average value above 0.3 indicates poor mental health of the person. It considers that the mental health status of family caregivers is not very ideal.

Conclusion: The study has a great deal of influence to society and even the world, it can not only enables people to focus on the special group (deaf children and their family caregivers), but also allow government to offer some feasible ideas to help relieve the situation, like curing the hearing-impaired children and providing support to family caregivers.
\end{abstract}

Keywords: hearing-impaired children, family caregiver, GHQ-12, mental health, monthly household income, the first child.

\section{INTRODUCTION}

Because many mothers are affected during pregnancy or genetic factors lead to an increasing number of children born with hearing impairment in the society, many institutions or civil organizations in the society spontaneously adopt or accept these children with hearing impairment. Hearing-impaired children do not have serious intellectual or emotional disorders, but they have hearing impairment. They need to use artificial hearing AIDS or acquire special and additional skills to overcome their obstacles. The daily life of hearing-impaired children also requires a lot of time and energy to be taken care of by family caregivers. However, they often neglect to take care of themselves because of taking care of their children. They are shrouded in a depressed and low atmosphere for a long time, concealing their true feelings and making their physical and mental health affected. Therefore, in order to understand the mental health status and influencing factors among family caregivers of hearing-impaired children, it is very necessary to collect and analyze the data in order to draw conclusions.

In the current study, I investigated the mental health status and influencing factors of family caregivers of hearing-impaired children.

\section{METHOD}

\subsection{Sampling}

The objects investigated in this research are family caregivers of hearing-impaired children from the kindergarten in Beijing Rehabilitation Center for 
Disabled Children and family caregivers of hearing-impaired children receiving treatment in the Care Centre. Family caregivers include parents, grandparents, nannies, and etc. These family caregivers come from all over the country to send their children with hearing impairment to the kindergarten for better medical conditions and learning environment.

\subsection{Procedure and measure}

Data about family caregivers of hearing-impaired children was collected through an anonymous online questionnaire. Information was collected on: i) demographic characteristics of family caregivers for hearing-impaired children, including age, gender, education, occupation and income), ii) care (the number of hearing-impaired children cared for, time spent caring for them, and relationship with children), and iii) mental health status of family caregivers. The GHQ-12 scale[1] (Goldberg, 1972) was used to assess mental health status of family caregivers. This scale was translated into Chinese and then sent out. All the analysis was performed using SPSS and the results were summarized.

\subsubsection{Response rate}

Questionnaires[5] were distributed to a total of 200 family caregivers of hearing-impaired children from the Kindergarten of the Rehabilitation Center of the China Disabled Persons' Federation (CDPF) and the Care Centre (an institution that trains hearing-impaired children), giving an overall response rate of 56.5\% (113 respondents).

\subsubsection{Participant characteristics}

Demographic characteristics participants' hearing-impaired children were summarized. The average age of the 113 subjects was 42 years old. The first variable is gender. There are 11 male participants, accounting for $10 \%$, and 102 female participants, accounting for $90 \%$. As for the second variable, there are 30 participants with junior high school education or below, accounting for $27 \%, 34$ participants with senior high school or technical secondary school graduation, accounting for $30 \%$, and 49 participants with bachelor degree or above, accounting for $43 \%$. The third variable is marital status: 3 people are unmarried (3\%), 99 people are married $(88 \%), 4$ people are separated $(4 \%), 7$ people are divorced $(7 \%)$ and no partner has died.The fourth variable is professional, 3 people are civil servants, accounted for $3 \%, 20$ people are professional and technical personnel, more than $18 \%, 11$ people are administrative personnel, accounted for $10 \%, 44$ people are service personnel, accounted for 39\%, 29 people are agriculture, forestry, animal husbandry and fishery production personnel, accounted for $26 \%, 6$ people are the production, transportation, equipment operation and related personnel, accounted for $5 \%$, no soldiers are included in the survey. The fifth variable is the monthly income of the family, the unit is RMB. There are 87 people with monthly household income between 5000 and 10,000 , accounting for $77 \%$; 18 people between 10,000 and 20,000 , accounting for $16 \%$; 2 people between 20,000 and 30,000 , accounting for $2 \%$; and 2 people between 30,000 and 40,000, accounting for $2 \%$; 4 people over 40,000 , accounting for $4 \%$.

Table 1 Basic information of participants

\begin{tabular}{|c|c|c|}
\hline Variable & frequency & $\begin{array}{l}\text { Percentage } \\
(\%)\end{array}$ \\
\hline Age & 42(mean) & \\
\hline Gender & & \\
\hline male & 11 & 10 \\
\hline $\begin{array}{l}\text { female } \\
\text { education }\end{array}$ & 102 & 90 \\
\hline $\begin{array}{l}\text { Junior high school } \\
\text { graduate or below }\end{array}$ & 30 & 27 \\
\hline High school or & & \\
\hline $\begin{array}{l}\text { technical secondary } \\
\text { school }\end{array}$ & 34 & 30 \\
\hline $\begin{array}{l}\text { bachelor degree or } \\
\text { above } \\
\text { marital status }\end{array}$ & 49 & 43 \\
\hline unmarried & 3 & 3 \\
\hline married & 99 & 87 \\
\hline separated & 4 & 4 \\
\hline divorced & 7 & 6 \\
\hline $\begin{array}{l}\text { spouse died } \\
\text { employment }\end{array}$ & 0 & 0 \\
\hline civil servants & 3 & 3 \\
\hline $\begin{array}{l}\text { professional and } \\
\text { technical personnel }\end{array}$ & 20 & 18 \\
\hline $\begin{array}{l}\text { administrative } \\
\text { personnel }\end{array}$ & 11 & 10 \\
\hline $\begin{array}{l}\text { production, } \\
\text { transportation } \\
\text { equipment operation } \\
\text { and related personnel }\end{array}$ & 44 & 38 \\
\hline military personnel & 29 & 26 \\
\hline service personnel & 6 & 5 \\
\hline
\end{tabular}




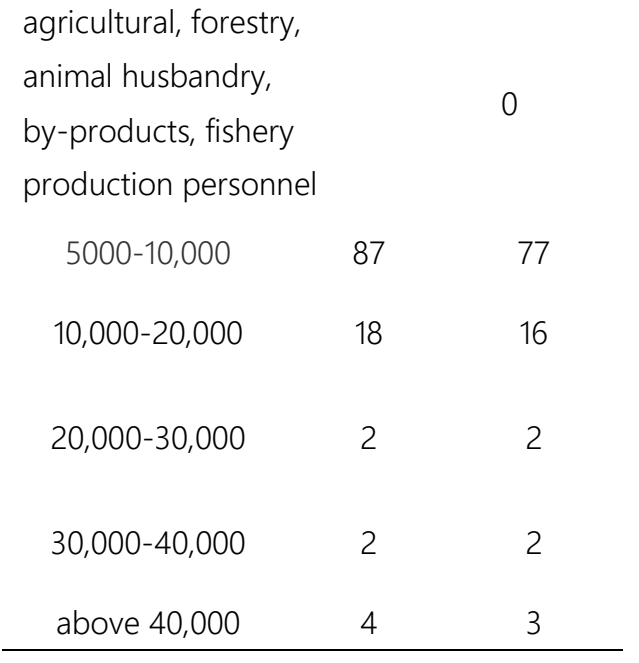

\subsection{Variables}

\subsubsection{Independent Variables}

Independent variables were factors affecting the mental health status of family caregivers for hearing-impaired children, including i) demographic characteristics of family caregivers (i.e., gender, educational background, marital status, occupation, monthly family income), ii) care (i.e., number of hearing-impaired children cared for, gender, age, illness, sick time, caring time, relationship with children).

\subsubsection{Dependent variable}

Dependent variable was the mental health status of family caregivers of hearing-impaired children. The mental health status of family caregivers of hearing-impaired children consists of 12 items[6] by asking participants whether they were happy, regarded themselves as valuable, whether to feel confident and feel depressed, can overcome the difficulties, can you make a decision, whether in the face of problems, whether focus ability, whether to enjoy everyday life, whether it can play a positive role in normal times, do you feel pressure, whether to have a good night's sleep. In addition, a total score of these 12 items (ranging from 0 to 12 ) was calculated and used as an overall indicator of mental health status of family caregivers.

\section{RESULT}

Table 2. Results of regression

\begin{tabular}{lrr} 
& & \\
Variable & Estimate & \multicolumn{2}{l}{ Std. } \\
& & Error \\
& & \\
\hline (Intercept) & 2.64308 & 6.107230 \\
& 33 & 2
\end{tabular}

\begin{tabular}{|c|c|c|}
\hline \multirow{2}{*}{ Age } & 0.04340 & 0.06790 \\
\hline & 23 & 08 \\
\hline \multirow{2}{*}{ Male } & 1.009717 & 1.2609 \\
\hline & 8 & \\
\hline Education & 0.016607 & 0.754 \\
\hline \multirow{2}{*}{ Married } & 0.36772 & 2.63061 \\
\hline & 44 & \\
\hline \multirow{2}{*}{ Separation } & -4.75119 & 4.8532 \\
\hline & 29 & $5 \varepsilon$ \\
\hline \multirow{2}{*}{ Divorced } & -1.73262 & 3.050182 \\
\hline & 01 & \\
\hline professional and technical & 0.157108 & 2.671819 \\
\hline personnel & 7 & \\
\hline \multirow{2}{*}{ administrative personnel } & -0.00069 & 2.93619 \\
\hline & 12 & \\
\hline production, & & \\
\hline transportation equipment & 0.666621 & 2.77805 \\
\hline operation and related & & \\
\hline \multicolumn{3}{|l|}{ personnel } \\
\hline military personnel & 0.666621 & $\begin{array}{r}2.86587 \\
75\end{array}$ \\
\hline \multirow{2}{*}{ service personnel } & 1.639593 & 3.096116 \\
\hline & 5 & \\
\hline monthly household & -0.90244 & 0.5283 \\
\hline come & 06 & \\
\hline
\end{tabular}

The number of children to $\quad 1.181867$

take care of

The first child's age

0.1858320 .321537

female

$-0.25948$

09

0.86945

The first child's grade

$-1.44764$

0.54723

The first child's state

$-0.52401$

0.42054

The first child's diagnosis

0.36079

time

0.54667

68

0.06897

The first child's care time

25

0.69092

43

41

Average time spent taking

$-0.06249$

0.37200

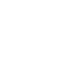

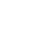

(1)

8

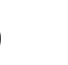

4

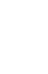




\begin{tabular}{|c|c|c|}
\hline Availability of other & 0.351406 & 1.088598 \\
\hline caregivers & 2 & 7 \\
\hline Variable & t value & $\operatorname{Pr}(>|t|)$ \\
\hline (Intercept) & 0.433 & 0.6668 \\
\hline Age & 0.639 & 0.5252 \\
\hline Male & 0.801 & 0.4266 \\
\hline Education & 0.022 & 0.9825 \\
\hline Married & 0.14 & 0.8893 \\
\hline Separation & -0.979 & 0.3317 \\
\hline Divorced & -0.568 & 0.5722 \\
\hline $\begin{array}{l}\text { professional and technical } \\
\text { personnel }\end{array}$ & 0.059 & 0.9533 \\
\hline administrative personnel & 0 & 0.9998 \\
\hline production, transportation & & \\
\hline $\begin{array}{l}\text { equipment operation and } \\
\text { related personnel }\end{array}$ & 0.24 & 0.8112 \\
\hline military personnel & 1.098 & 0.2767 \\
\hline service personnel & 0.53 & 0.5984 \\
\hline monthly household income & -1.708 & 0.093 \\
\hline $\begin{array}{l}\text { The number of children to } \\
\text { take care of }\end{array}$ & 0.725 & 0.4713 \\
\hline The first child's age & 0.578 & 0.5655 \\
\hline female & -0.298 & 0.7664 \\
\hline The first child's grade & -2.64 & $0.0105^{*}$ \\
\hline
\end{tabular}

\begin{tabular}{|c|c|c|}
\hline The first child's state & -1.246 & 0.2178 \\
\hline $\begin{array}{l}\text { The first child's diagnosis } \\
\text { time }\end{array}$ & 0.66 & 0.5119 \\
\hline The first child's care time & 0.1 & 0.9208 \\
\hline Average time spent taking & & \\
\hline $\begin{array}{l}\text { care of } \\
\text { children per day }\end{array}$ & -0.168 & 0.8672 \\
\hline $\begin{array}{l}\text { Availability of other } \\
\text { caregivers }\end{array}$ & 0.323 & 0.748 \\
\hline $\begin{array}{l}\text { The relationship with the first } \\
\text { child }\end{array}$ & 0.858 & 0.3943 \\
\hline
\end{tabular}

Table 2 shows the relationship between mental health status of family caregivers and influencing factors. When the significance is less than 0.1 , it means that the relationship between the dependent variable and the independent variable is significant; otherwise, it is not significant. The positive value of estimates indicates that the mental health of the subjects is worse when the level of the independent variable increases. The negative value of estimates means that the mental health of the subjects is better when the level of independent variables increases. It can be seen from the table that: 1) the estimate of monthly household income is -0.9024406 , and its $p$-value is 0.093 . It means that each unit increase in the monthly household income of the caregiver in the family was associated with better mental health ; and 2) the estimate of the first child's grade is -1.4476435 , and the p-value is 0.0105 . It states that the older the first child is, the better the mental health status of his/her family caregivers. Only the above two conclusions are universally applicable, since the significance index of monthly household income is $0.022(<0.1)$, the significance index of The first child's grade is $0.046(<0.1)$.

Table 3. Results of GHQ-12 scale

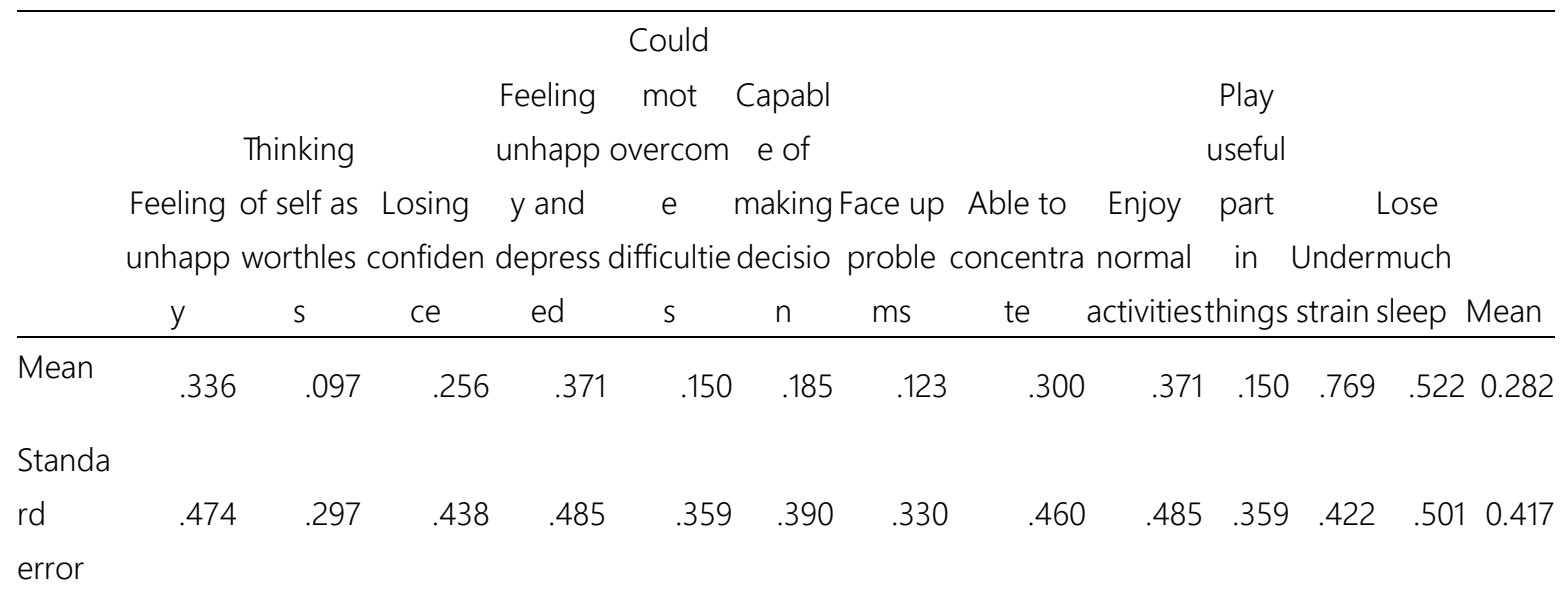

It can also be seen that there are no significant relationship between other independent variables and the dependent variable. $P$ values of age, male, separation, administrative personnel, the grade of the second child, the illness of the second child, the diagnosed time of the first child, care time of the second child, the amount of 
carers, the relationship between carer and the first child and the relationship between carer and the second child are above 0.1 .

The GHQ-12, is a screening tool used to recognize the severity of psychological distress experienced by an individual within the past few weeks. This scale focuses on breaks in normal functioning rather than on life-long traits; therefore, it only covers disorders or patterns of adjustment associated with distress. Each item on the scale has four responses from 'better than usual' to 'much less than usual'. As for the purpose of this study, the GHQ scoring method (0-0-1-1) was chosen ,as this particular method is believed to help eliminate any biases which might result from the respondents who tend to choose responses 1 and 4 or 2 and 3 , respectively[1] (Goldberg \& Williams, 1988). The scores were summed up by adding all the items on the scale ranging from 0 to 12 .

It can be seen in Table 3 that: 1) The average value above 0.3 indicates poor mental health of the person: the average values of Feeling unhappy, Feeling unhappy and depressed, Being able to concentrate, Enjoying normal activities, Under strain and Loss of much sleep are all greater than 0.3 ; while the average values of Thinking of self as worthless, Losing confidence, Could not overcome difficulties, Being capable of making decision, Facing up problems and Playing useful part in things are lower than 0.3 . The average of feeling unhappy is 0.3363 , but it's greater than 0.3 , so more people are not happy; The average of thinking of self as worthless is 0.0973 , less than 0.3 , so it means that more people think they are valuable. The average value of Losing confidence is 0.2566 , less than 0.3 , which means more people feel confident. The average value of feeling unhappy and depressed is 0.3717 , with scores greater than 0.3 indicating more people were depressed; The average score of could not overcome difficulties is 0.1504 , less than 0.3 , which indicates that more people feel able to overcome difficulties. The average score of capable of making decision is 0.1858 , less than 0.3 , which means more people are

able to make decisions. The average score of face up problems is 0.1239 , less than 0.3 , which means more people are able to face problems. The average score of able to concentrate is 0.3009 , greater than 0.3 , which means that more people think that their

ability to focus is not very good; The average Score of enjoying normal activities is 0.3717 , greater than 0.3 , indicating that more people are unable to enjoy their daily life. The average Score of Playing useful part in things is 0.1504 , less than 0.3 , which means that more people think they play a positive role in normal times. The average Score of 11 is 0.7699 , greater than 0.3 , which means that most people feel stressed. The average Score of 12 was 0.5221 , greater than 0.3 , indicating that more people rated their sleep quality as poor. The average value of all 12 indexes is 0.282 , which is less than 0.3 ; and the mean of standard error is 0.417 , which is greater than 0.3 .

\section{DISCUSSION}

In table 2, the analysis of two data results is significant. We can conclude that each unit of increase in the monthly household income of the family caregiver was associated with better mental health; and the older the first child is, the better the mental health status of his/her family caregivers. According to the data results, other factors are not significant. Like age, male, education, married, separation, divorced, professional and technical personnel, administrative personnel production, transportation equipment operation and related personnel, military personnel, service personnel, the number of children to take care of, the first child's age, female, the first child's state, the first child's diagnosis time, the first child's care time, average time spent taking care of children per day, availability of other caregivers, the relationship with the first child.

In Table 3, these averages are generally above 0 , and some of all are close to 1 . The higher the mean score, the worse the mental health of the family caregiver. The average value of all 12 indexes is 0.282 , and the mean of standard error is 0.417 . In table 3 , the highest score of those mean are Under strain and Losing much sleep; It shows that more people are suffering from a lot of stress and do not get enough sleep in their daily life which leads to psychological problems. Also the lowest score of those mean are Thinking of self as worthless, Could not overcome difficulties and Playing useful part in things. It states that they are still a variety of people consider that they are valuable, they can overcome some difficulties in reality and they are playing useful part in things. This, in turn reflects better mental health.

\section{CONCLUSION}

My study showed that among family caregivers for hearing-impaired children, each unit of increase in the monthly household income of the family caregiver was associated with better mental health; and the older the first child is, the better the mental health status of his family caregivers. The results of the study greatly affect the society and even the world, it can promote people to focus on understanding these two types of special groups, allowing people to offer better ideas to help the family caregivers, keeping them in a good mental health state. Therefore, the government can issue relevant policies and decrees to reasonably and legally protect hearing-impaired children and their family caregivers, and provide them with better resources and environment for treatment and care.

\section{REFERENCES}

[1] Goldberg, D. (1972). The detection of psychiatric 
illness by questionnaire: A technique for the identification and assessment of non-psychotic psychiatric illness. London, New York: Oxford University Press.

[2] Goldberg, D., Oldehinkel, T., \& Ormel, J. (1988). Why GHQ threshold varies from one place to another. 28(04), 915-921.

[3] Cheung, Y. B. (2002). A confirmatory factor analysis of the 12-item General Health Questionnaire among older people. International Journal of Geriatric Psychiatry, 17, 739-744.
[4] Dahlin, M., Joneborg, N., \& Runeson, B. (2005). Stress and depression among medical students: a cross-sectional study. Med Educ, 39, 594-604.

[5] Daradkeh, T. K., Ghubash, R., \& El-Rufaie, O. E. (2001). Reliability, validity, and factor structure of the Arabic version of the 12-item General Health Questionnaire. Psychol Rep 89, 85-94.

[6] Field, A. (2005). Research Methods II: Factor Analysis on SPSS. [Online] Available:

http://www.sussex.ac.uk/Users/andyf/teaching/rm2 / factor.pdf ( 30th August 2021). 